\title{
E-Tutorials as an Addition to Higher Education Learning Scenarios
}

\author{
By Carsten Lecon* \\ Bernd Oder ${ }^{\dagger}$
}

At universities, we observe a great range of variation in previous knowledge and decreasing mathematical competences of students - partly due to less limited qualification rules at universities in Germany.

To address the challenges which arise by teaching very heterogeneous student groups we use e-tutorials as an addition to traditional classroom teaching. We show how virtual $3 D$ rooms should be constructed for the purpose of etutorials. Based on our experience we discuss advantages and limitations using virtual $3 D$ rooms in university teaching.

Keywords: e-learning, e-tutorial, education of mathematics, virtual 3D room

\section{Introduction}

Classroom teaching is still the traditional method knowledge transfer at universities - partly completed by self-study and further ways. The advantages are obvious: Problems of understanding and misunderstanding concepts can be solved spontaneously in a one-to-one conversation, completed by additional explanations and examples. However, because of the lower conditions of admissions in Germany, we observe increased heterogeneous previous knowledge in computer science especially concerning mathematical skills. But a desirable all-embracing individual face-to-face assistance cannot be realized.

However, in order to give students more support, there already exist some helpful possibilities - although with certain limitations:

- Online courses: Self-made or - for example - via YouTube. Online courses can be used in addition to classroom teaching. Teaching material can be offered on different levels of difficulty and by different media; the students are able to determine their best learning path. However, it is very time-consuming to create online courses; and in general there is no supervision by a tutor, which could be helpful especially in the beginning of studying.

- Tutorials are well suited to recapitulate and deepen the learning syllabus in small student groups. However, because of the full timetable

\footnotetext{
* Professor, Aalen University, Germany.

${ }^{\dagger}$ Study Support Center, Aalen University, Germany.
} 
- especially in the first semesters - students sometimes find it difficult to make appointments for common meetings during daytime.

- Individual consultation-hours are very effective for students, but very personnel-intensive.

Another problem at our Aalen University of Applied is its geographical location. The university is located far away from big cities in a rural environment. Most of the students as well as the tutors are not living nearby our university but rather in the surrounding villages. Normally, the daily timetable is filled with only a few gaps, so that there are hardly any opportunities to meet for group activities or for additional events like tutorials. As soon as the lectures are over students usually return home and usually will not come back for an evening meeting.

To address the challenges we use e-tutorials in virtual 3D rooms as an addition to traditional classroom teaching which are all linked by a learning management system (LMS) like Moodle or ILIAS. With this new technique, we offer a new possibility for location-independent teaching (Figure 1).

Figure 1. Possible Learning Sites

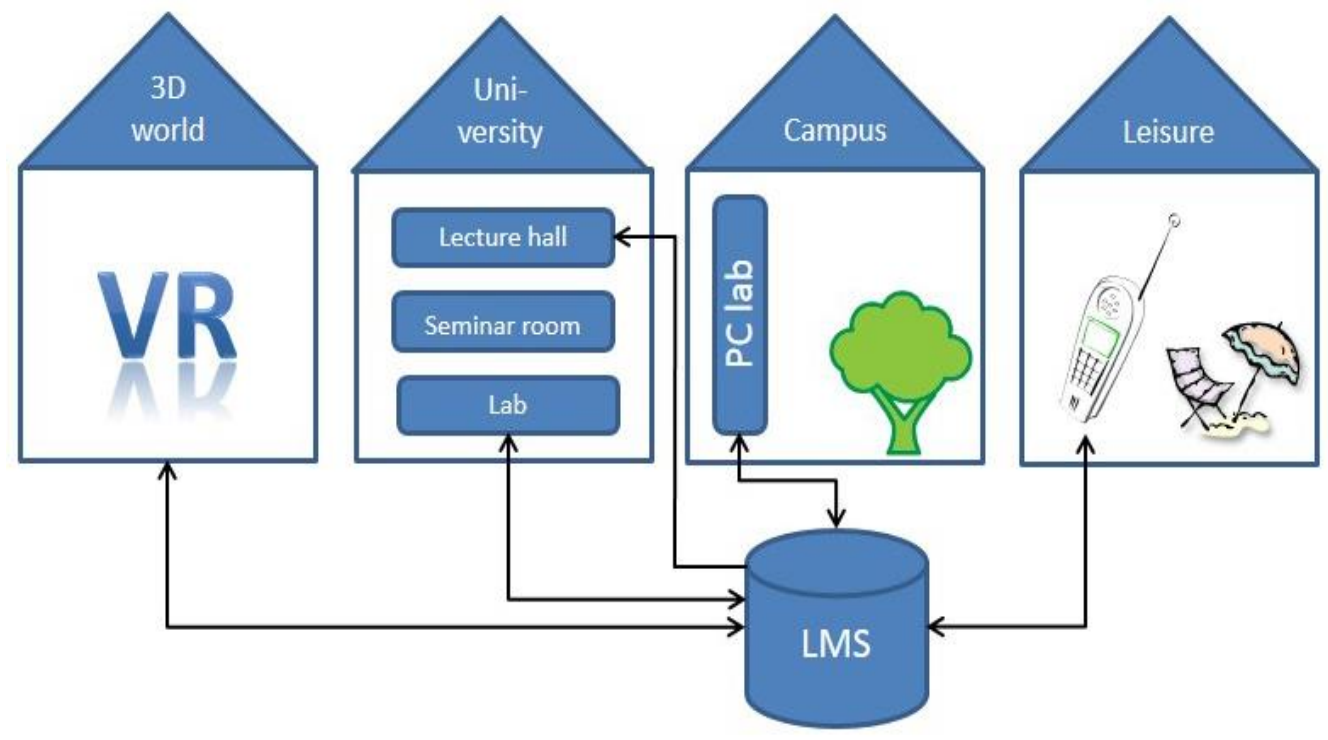

Source: Prepared by authors.

\section{Methodology}

The positive effect of using virtual 3D worlds in simulations and training competences has been proved (Moskaliuk, Bertram, \& Cress, 2013). Virtual $3 \mathrm{D}$ worlds are used at universities mainly for the visualization and simulation of complex issues (Trindade, Fiolhais, \& Almeida, 2002). The transfer of traditional classroom teaching into a complete virtual environment is still unfamiliar and not often practiced. Our proposition is that learning and working in a virtual 3D environment, in some cases, can improve the learning 
success or at least the motivation of the students. In order to analyze this theory we have offered some additional learning scenarios, so called e-tutorials, which are held in virtual 3D rooms. First approaches in this direction can be found in a project for teaching in middle schools (VLE, 2012).

As a subject, we have chosen the - supposedly - most difficult fundamentals in mathematics.

The students were free to use this additional option. The sessions in the virtual 3D room took place in the evening at strategic meaningful times: Either before (intermediate) exams or in case of increased difficulties in the understanding of the subject matter. Hence, many students (about 75\%) used this possibility to deepen the learning matter.

Simultaneously, virtual 3D rooms were used in a media computer science lecture in order to initiate collaboration (group activities). In addition, we consider the results of another collaboration project in a virtual 3D environment (Lueckemeyer, 2015).

Table 1 shows how many students have participated in the respective virtual 3D rooms; the lectures were "Fundamentals in Mathematics" $\left(1^{\text {st }}\right.$ semester), "Calculus" ( $2^{\text {nd }}$ semester) and "Animation and Virtual Reality" ( $7^{\text {th }}$ semester). Because learning in a large group is not effective, we have offered two sessions for each lecture; for example, in "Fundamentals in Mathematics" one group had 24 , the other 19 participants.

Table 1. Virtual 3D Room: Participating Students

\begin{tabular}{|l|c|c|c|}
\hline Semester & Found. Math. & Calculus & Animation \& VR \\
\hline SS 2014 & $24+19$ & & $21+11$ \\
\hline WS 2014/ 2015 & & $18+18$ & \\
\hline SS 2015 & & & 14 \\
\hline
\end{tabular}

Source: Authors' estimation.

In order to analyze the effects in using this rather new medium we used a qualitative questionnaire for evaluation. These included questions about the technique (simplicity of the installation, network lags ...), about the user interface as well as the perceived learning effect. In addition, we analyzed the results of the taken exams: Indeed the learning matters, covered in the etutorials in more detail, were handled more effectively in the examinations.

The results of the questionnaire are outlined in the chapter "Experiences"; the questionnaire (in German) can be found in the appendix.

In the following, we now present our approach to integrate virtual 3D rooms in the university curriculum. 


\section{Virtual 3D Rooms for E-Tutorials}

\section{Integration into the Timetable}

At our university, some additional tutorials for elementary mathematics take place as an e-tutorial. E-tutorials are tutorials offered in virtual 3D rooms: E-tutorials "expand" the university building to home buildings.

The great advantage is that the appointment time for students and tutors can be determined very flexibly, because the presence of students and tutor at the university is not necessary, and no class rooms have to be occupied (for example, in the evening at the university, the maintenance supervisor locks the doors at the campus, etc.) The students can participate while being home - they do not have to reside at the university in person. Naturally, students can also use computers in the university labs (when open). That is if they are at the university anyway, if they need some advice or have no possibility to use the virtual world from home because of technical restrictions.

Figure 2 shows when the classroom teaching and the e-tutorials typically take place. While traditional lectures and accompanying tutorials are scheduled during the curriculum, the e-tutorials take place in the evening - or at the weekend if necessary. The e-tutorials are mainly used to recapitulate the issues of real tutorials and to address questions of students.

Figure 2. Timetable for Presence Tutorial and E-Tutorial

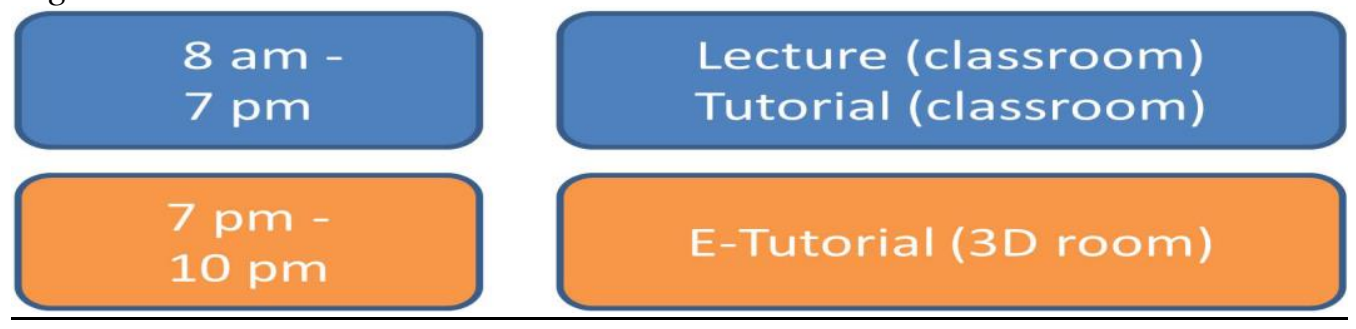

Source: Prepared by authors.

\section{Technical Implementation}

As a virtual 3D room we used TriCAT Spaces provided by the company TriCAT $\mathrm{GmbH}^{1}$ (Ulm, Germany), which is a rentable web application (Saas: Software as a Service) (Lecon \& Herkersdorf, 2014).

In order to address as many students as possible it was necessary to minimize the technical requirements on the client side: Only an internet access and a headset were required. Nowadays, most of the students have internet access (normally flat rate) and earphones; using an integrated microphone is recommendable in order to avoid acoustic feedback.

\footnotetext{
${ }^{1}$ http://www.tricat.net/
} 


\section{Features of the Virtual 3D Room}

The setting of the virtual room is commodious and bright and contains the usual equipment. There are a foyer, seminar rooms, a conference room, and an exterior area e.g. for recreation. Looking outside the virtual windows, one can see (and hear quietly) a silhouette of a large town: The perceived virtual world does not end behind the windows (Figure 3).

Figure 3. Example of a Virtual 3D Room Setting

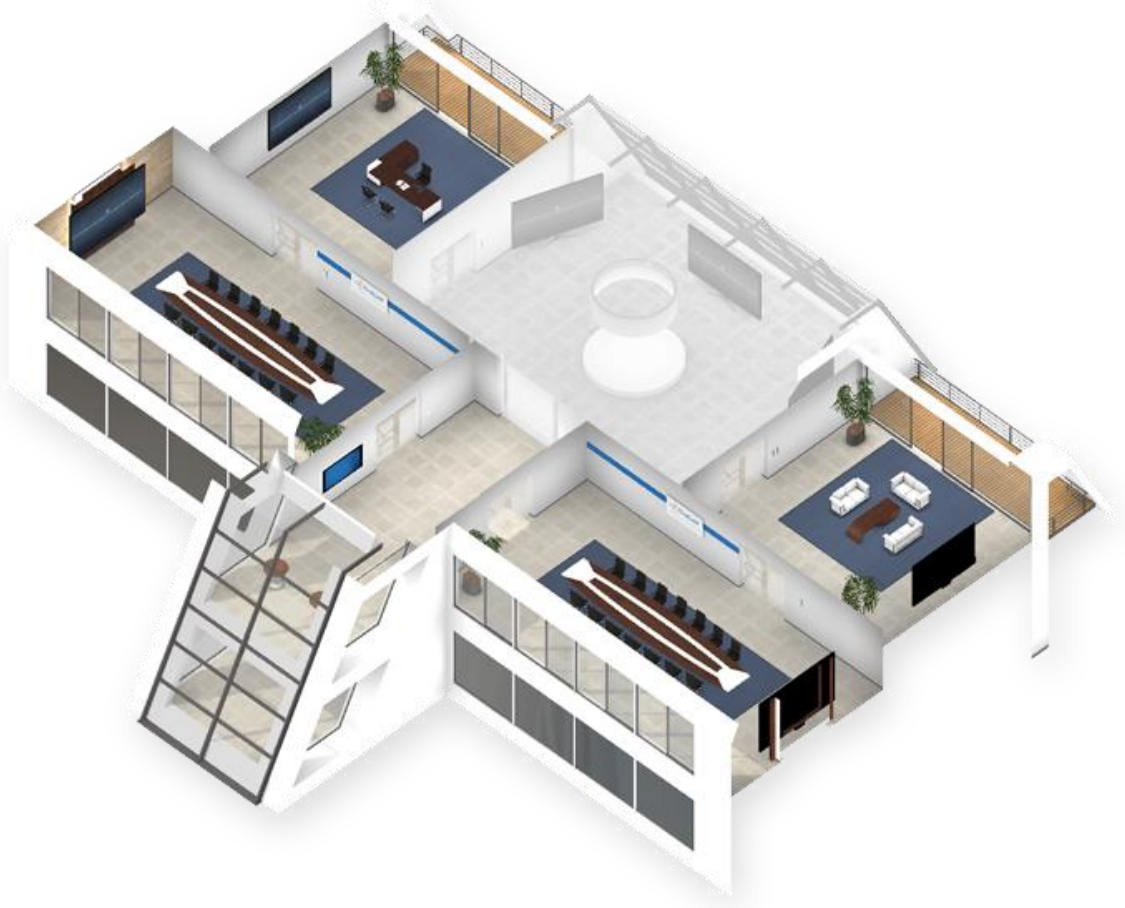

Source: Prepared by authors.

The artificial environment can be adapted to the individual needs of the learning subject. Using "just" software, it is possible to construct the learning environment for the specific learning scenario in any way needed. This concerns the number of rooms, the equipment like tables, chairs, outdoor areas, items. On the other hand, via virtual rooms studentsa can focus only on the essential aspects of learning. There is no distraction by flashy pictures, birds flying outside the room or normal noises (street noise, sounds of electrical equipment like a beamer, and even whispering or sounds, which arise when typing on a mobile phone). During sessions, additional visual objects (equipment, wall colour, fog...) as well as acoustic effects (background sound, warning bell...) may be supplemented.

In virtual 3D rooms the learners present themselves as avatars, that is abstract copies of themselves (see Figure 4 and 5). We provided a selection of 42 different characters, which the users were able to customize in terms of 
color of clothes, accessories like hats and bags. Mechanisms to control the avatars were adopted from mechanisms of computer games. The perceived perspective of the user is consistent with the viewing direction of the avatar: All avatars see the same surrounding in their virtual world. Therefore, they can look and point to identical things making it possible to experience a strong social and spatial presence - the so-called co-presence (Lombard, \& Ditton, 1997): The students can see each other; they observe the same spatial environment and hear the same background sound. The viewpoint in the 3D room is a first person view. Hence, the students see the same perspective like in a real environment which confirms the feeling of immersion. The avatar can be controlled by keyboard and computer mouse. Some nonverbal aspects are simulated by fading in appropriate icons: voting by hand signals, clapping, smiling. Apart from that communication is done by audio or text chat like in telephone conferences.

All noises (speech, noise of walking, sounds from the media wall, background noises from outside...) are stereoscopic, and the perception of the sound fits the direction and the distance of the source of the sound. The individual rooms are decoupled, i.e. the sound of one room cannot be heard in another room. Thus, conversations can be held in several rooms simultaneously.

Figure 4. E-Tutorial (Three Media Walls)

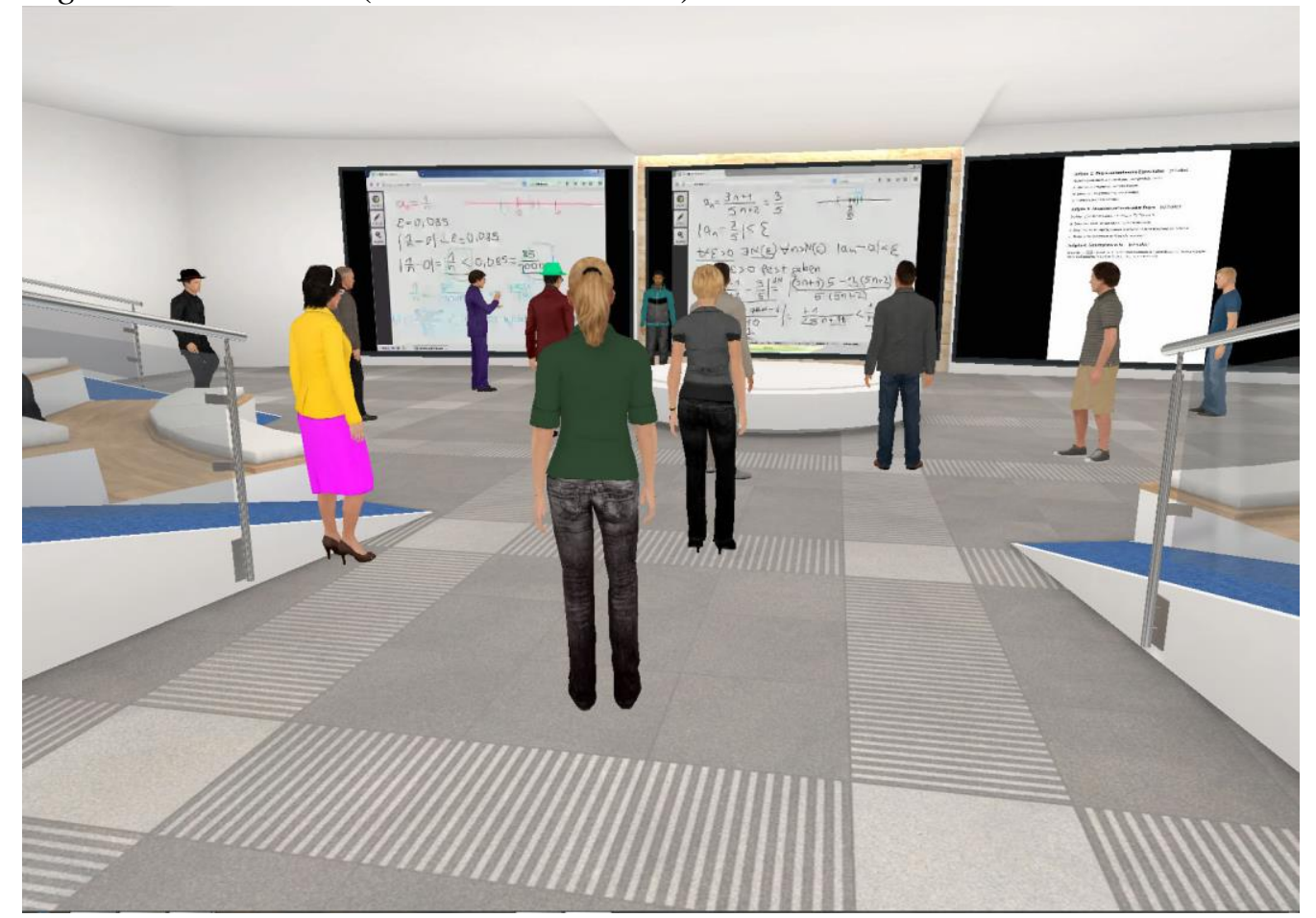

Source: Prepared by authors.

So-called media walls (see Figure 4) serve as a presentation displays for any media, internet sites as well as remote desktop applications. Since the 3D software possesses various interfaces to other software programs including the 
internet, it is possible to use application-sharing scenarios and contents from a learning management system. Furthermore, animated 3D models may be viewed (holodeck), interaction and manipulation with these models are possible. Hence, in e-tutorials students can communicate in the same way as in real seminar rooms - by voice (headset), whiteboard or text chat.

Even metacognition can be supported, e.g. observing working students by a tutor: Working in virtual 3D rooms, students can be observed by the tutor how they are acting and where they are experiencing problems. At best, students explain their course of action. By this (explaining and being observed), students are more aware of their problem solving methods.

Topics to be learned can easily be correlated to environmental stimuli, for example teaching the "algorithm bubble sort" correlates with the "yellow shirt of the teacher". It is shown that the recall of trained skills is more sustainable if it is learned in an associating context. The virtual room has therefore psychological effects as well; it emotionalizes and hence influences the learning process (Aslan, Samenieh, Staudig, \& Bäuml, 2012).

Known technical environment can be used like an interactive whiteboard, application sharing, remote desktop. Students can even use their own tools in virtual rooms, for example IDEs (Integrated Development Environments), 3D modelling tools, animation and video tools, word processing tools, social networks (PEW Research, 2014).

Virtual sessions can be recorded and replayed as a video afterwards. Multiple sessions can take place simultaneously, for example to examine different group compositions. The tutor can afterwards evaluate the sessions one after another. Furthermore, a recorded session can be reused as an audiovisual training object, and, additionally, the session may be viewed out of different perspectives by moving the virtual camera, e.g. from the point of the tutor or a selected student or a bird's eye view.

In order to analyze the progress of learning (and working as well) all activities which take place in the virtual rooms can be tracked: Spoken comments, presented learning contents, avatar movements or results of quizzes. Analyzing the tracked data, some aspects of group activity can be measured automatically, for example the length of spoken comments, moving behavior. The quality of given comments is be judged by the author.

In order to track these activities we used the rather new Tin Can $\mathrm{API}^{2}$.

\section{Further Possibilities of Virtual 3D Rooms}

There exist further possibilities using virtual 3D rooms, which primarily do not regard e-tutorials in our curriculum.

Things can be made visible which are normally invisible, e.g. electric fields, molecules or airflow. 3D objects which do not exist so far (prototypes of cars or of machines...) can be presented. In order to allegorize e.g. the pollution of the environment (e.g. concentration of nitrogen in Beijing) pending

\footnotetext{
${ }^{2}$ http://tincanapi.com
} 
balls can be simulated. Or, for example, the visualization of empathy and antipathy through the position and size of geometric objects (e.g. systemic structural constellations) is easily possible. Moreover, in general one can realize (animated) visualization of complex facts - with the possibility of spatial experiencing.

The training of unlikely situations is possible in a benign environment and without costs of material.

Parameters of the environment, e.g. the number of rooms, the colour of the walls or of things, the weather, lighting conditions or error messages from machines can easily be adapted to special need.

For example, the following feature is used for training situations by the police in Baden-Württemberg in southern Germany: A virtual world with an area of 100 square kilometres of artificial landscape has been developed for virtual training (Mantovani \& Castelnuovo, 2003). After completion of the training, the recorded session can be evaluated out of different perspectives (overall point of view, police officer's or helicopter's viewpoint).

\section{Experiences}

\section{First Contact to Virtual 3D Rooms}

However, even if the virtual sessions take place at "student-conform" times, students have to spend some hours of their spare time. Therefore, a strong benefit has to be recognizable to them. In our context, we used etutorials at "strategic" meaningful points of time: Before intermediate testing and exams, and in case of increased difficulties in understanding the subject matter.

At first, integrating virtual 3D rooms into the traditional classroom, teaching was unfamiliar. As a reaction we expected cautious interest, disinterest up to resistance. However, the actual reaction was a curious interest; students wanted to try out this new medium. We observed that students soon considered the virtual world as the actual learning place like in computer games: Experiencing a so-called "flow" (Csikszentmihalyi, 1990).

When using virtual 3D rooms for e-tutorials, it is important that students are familiar with controlling avatars and all possibilities in 3D rooms. Therefore, we gave a short introduction tutorial. As a result, students had no problems to act in the virtual room afterwards.

Nevertheless, this medium itself was somewhat unfamiliar. At the beginning of the first session, students ran through the virtual rooms and tried out everything. It seemed that this playful approach led to a positive mood. However, after some time the tutor had to stop them playing around and had to prompt them to start working. After this adaption phase, working in the virtual room was very intensive. Most of the students said that they forgot the real environment at home or in the lab and experienced the virtual room as the actual working and learning place. 
The great advantage - in contrast to classroom teaching - is the flexibility of time and location. The students act from home and can even use their own technical equipment due to the rather low technical requirements of the virtual rooms in use.

\section{Behaviour in the Virtual 3D Rooms}

We expected that introverted students were more willing to participate actively compared to the real environment, because the students are presented as an abstract copy of themselves - the avatars -, which serve as a "protective shield": The avatars are an anonymous copy of the real person with limited facial expression and gesture. By this way discussions might run more objective, because one is not influenced by non-verbal communication (other persons do not see the "red face"). Moreover, looking outside the window, lost in thought, one does not feel to be cornered. So, it is not likely that introverted or shy people felt embarrassed like in the real world. Therefore, the inhibition threshold of making errors could be higher, because one is not affected personally.

However, it became apparent that this was not the case. Perhaps this was because the students knew each other very good.

A usual face-to-face communication is not possible. However, this might be an advantage: The students can be dressed casually being in the virtual room, they can have a small dinner, etc. - no one can see it. Like in social networks the avatars are a kind of "nickname", one can choose an individual appearance of the avatar. This leads first to a funny first approach that automatically leads to a pleasant atmosphere: In the first virtual session the students can choose their appearance - sometimes very flashy, as seen in Figure 5.

Figure 5. Individual Appearance of the Avatars

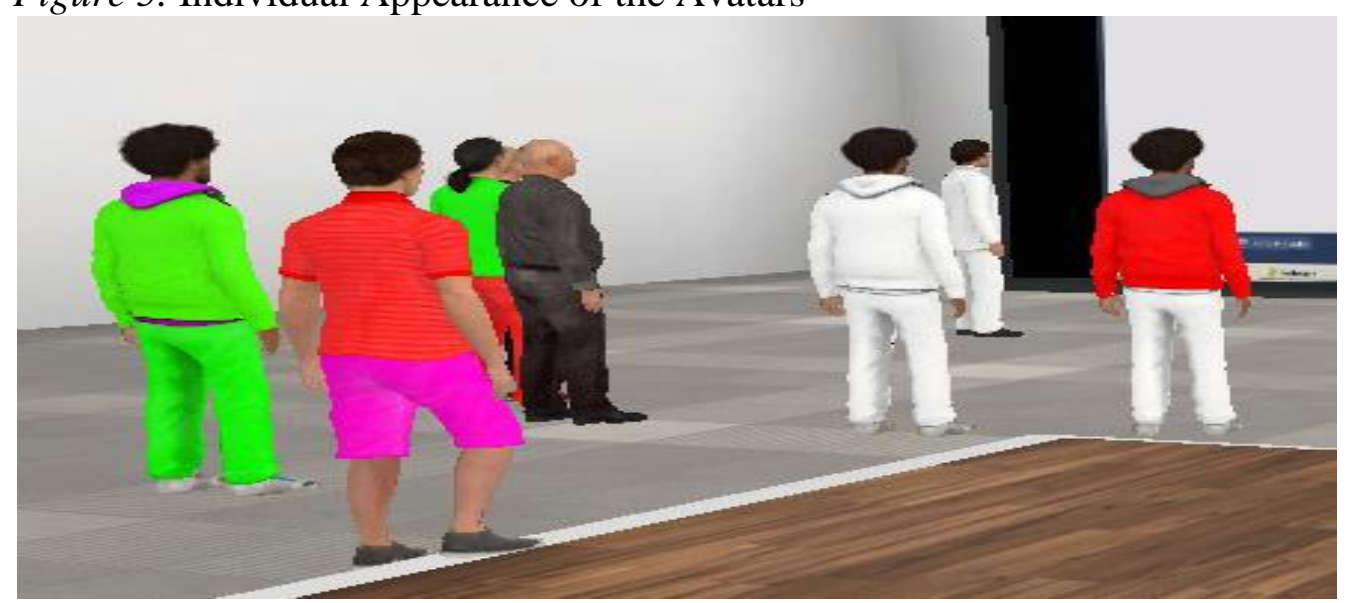

Source: Prepared by authors. 


\section{Group Activities}

The learning process is often more sustainable if the learning takes place in the setting of group activities. Not only practical project activities can be done in groups, but also the collaborative problem solving of exercises in a tutorial. However, in general there exist some challenges regarding cooperation: Social facilitation and theory of critical mass. Virtual 3D rooms can be used to cope with these challenges:

- Social facilitation: If a person has experiences in doing the required task, she or he will act better, when the other persons are watching her or him. On the other hand, if a person is untrained or new in this subject, it is likely that the productivity is restricted in the presence of other people. We hope that for the people representing themselves as avatars, the inhibition threshold to make errors might be higher as in the real word because of the anonymity.

- Theory of critical mass (Macy, 1990): The motivation to interact in a group is depending on the critical mass. A specific number of participants, who do actively cooperate, is needed to complete common tasks in the group. Therefore, it is important that from the very beginning, a challenge has to be performed cooperatively. In a virtual $3 \mathrm{D}$ room, it is difficult to hide, because all students are more visible and therefore it might be more likely for them to participate.

\section{Result of the Evaluation}

In the final evaluation, the students submitted some suggestions:

- When communicating, a push-to-talk should be possible; currently the microphone is open the whole time.

- Especially in a highly interactive meeting like a virtual tutorial, it is important to be able to "write" on the media walls easily. Lags - caused by networks lags or difficulties using the input device - hinder the continuous concentration of the students. Therefore, an adequate online user interface should exist, and those using this tool should be trained.

- Especially our tutor himself has criticized the lack of gesture and facial expression. An experienced tutor notices the understanding/ not understanding based on the student's facial expression.

- The students see great potential in using virtual 3D rooms - if no networks problems occur, a simple user interface is available, and/or the possibility to record a session is given.

- The students can view better the use of virtual 3D rooms for group work.

- A break should be scheduled per hour.

- After all, the flexibility of location (and time) has been emphasized. 


\section{Deficiencies and Limitations}

There exist some challenges and limitations using virtual 3D rooms as well.

In particular in the earlier stages of using 3D rooms the virtual room was a copy of the real building (campus metaphor). However, users are irritated if the artificial representation does not fit the real building exactly. Thus our virtual world is an abstract world - with pleasant rooms flooded with light and equipped with the furniture and tools as desired for the specific learning or working task. In the future, the avatars will get facial expression and gesture. While tools exist to imitate the feeling, the corresponding reaction does not occur as spontaneously as in the real world.

Although the students are visible as avatars, it is not certain if the person is present: It might be that she or he has logged in and has then moved from the PC. Typically, the avatars are slightly moving - even if they are not moved by the user - and the absence of the real person is not noticed for some time.

The artificial communication, the lack of facial expression, gesture, eventually even smell can influence the communication. The direct visual feedback is missing.

In addition, of course, the technical implementation can be a problem. For example, internet bandwidth, missing earphones or microphones, special software that has to be installed. In addition, the maximum count of participants in our prototype was actually limited to 20.

Furthermore, the user interface may be unfamiliar or difficult for some users. In this regard, gamers have a clear advantage because they are used to move avatars in three-dimensional environments (moving avatars in 3D learning environment is comparable with moving figures in computer games).

An essential learning effect is still not proved up to now (in training scenarios the effect is already shown (Mantovani \& Castelnuovo, 2003), however, the flexibility of location and time indicate the use of virtual 3D rooms.

One important aspect in university life is the communication during the breaks between "normal" meetings - with coffee and cookies. This cannot be mapped to virtual 3D rooms: Virtual coffee is not as good as real coffee.

And, students are used to communicate via smartphones and other mobile devices. Although virtual 3D rooms are working on these devices, rather small displays and limited interaction possibilities (small buttons, etc.) do not match the ideal learning environment (for example the spatial presence is very limited).

Finally, one important challenge in using virtual 3D rooms is the cost. It is very time-consuming and costly to create a virtual 3D room. Therefore, the virtual world has to be bought or rented (as in our case); both are costintensive. 


\section{Further Work}

We will adopt the e-tutorials according to our experiences. For example, we will make the optional participation of the virtual tutorial obligatory. For that, even introverted students cannot absent themselves from the e-tutorial. Furthermore, we will use a graphics tablet for an easier input of written text, especially formulas, on the media wall. The exchange of students in groups will be done simultaneously in different (virtual) meeting rooms.

We will integrate Gamification elements (Hamari, Koivisto, \& Sarsa, 2014) like quizzes, solving exercises as fast as possible in the e-tutorial.

In order to improve the quality of the tutorials, the training of tutors (train the trainer) plays an important role. Here virtual 3D rooms offer advanced possibilities. While performing a virtual tutorial, different situations can be simulated; people slip in different roles: One avatar can act as a troublemaker, one can ask questions repeatedly, and another avatar can show disinterest. Either real persons slip into these roles, or the avatars are controlled by artificial intelligence. In this way, a tutor can prepare himself for difficult situations - in a benign environment.

It is planned to offer consultation-hours in virtual 3D rooms. A tutor will be available on demand. In this way, the students can get assistance when they are working on their homework - at home.

Furthermore, e-tutorials can be used in advanced lectures. We already use virtual 3D rooms as a supplement to the classroom teaching for group activities in a media computer science lecture: One educational objective of the course is modelling (by teamwork) and controlling a 3D robot. The challenge is to write an algorithm so that the robot collects items as fast as possible. Since students can compare their results directly in the 3D room, this leads to highly motivated working and learning (high score incentive - a kind of Gamification). Such a playfully approach can be used in e-tutorials for this lecture as well, for example by filling in a cloze of the program code for the virtual robot. By this way, some aspects of computer graphic and animation can be learned: Kinds of animated rotation (e.g. Euler angles, Quaternions) or programming languages for implementation of animations (e.g. Java3D, CSS3, POV-Ray).

Another project named "Software Explorer" has just started at our university. The intention of this project is to visualize complex software structures by $3 \mathrm{D}$ objects and by navigating through packages, classes, methods and other programming constructs. The underlying technique is compatible with the virtual 3D world, which we use for the e-tutorials. We hope that the students achieve a better awareness of complex software structures and determine easier and more clearly where the code can be improved or minimized. Some already existing works in this field are listed for example in (Teyseyre \& Campo, 2008). 


\section{Conclusion}

The positive effect of using virtual 3D worlds in simulations and training competences is proved (Mantovani \& Castelnuovo, 2003; Moskaliuk, Bertram, $\&$ Cress, 2013). Furthermore, these worlds are suitable also for the integration in university curriculum, which normally consists of lectures in presence. Learning activities, which usually take place in a lecture hall or seminar room, are done in a virtual environment. Since the usual face-to-face learning phases are transferred into the virtual 3D world, we call this concept Virtual Blended Learning (Lecon \& Herkersdorf, 2014). Virtual 3D rooms are a good addition - and ideal improvement - of traditional classroom teaching and online learning, especially because of the flexibility of location and time. In addition, there exist some useful features like configurable spatial environment, recording and replaying of sessions, tracking of all learning activities. In this spirit, the virtual 3D world is a toolbox. The target of using virtual worlds should be to facilitate learning.

Perhaps virtual 3D rooms can even become the central entry point for any learning activities like Personal Learning Environments (PLE) (Softic et al., 2013) nowadays.

\section{Acknowledgments}

This work was funded through the IQF Funding Program of the federal state of Baden Wuerttemberg (Germany) ${ }^{3}$.

\section{References}

Aslan, A., Samenieh, A., Staudigl, T., \& Bäuml, K.-H. (2010). Memorial consequences of environmental context change in children and adults. Experimental Psychology, 57, 455-461.

Csikszentmihalyi, M. (1990). FLOW: The psychology of optimal experience. New York: Harper Perennial Modern Classics.

Hamari,J, Koivisto, J., \& Sarsa., H. (2014). Does gamification work? - A literature review of empirical studies on gamification. Proceedings from 47th Hawaii International Conference on System Sciences, Hawaii, USA, Jan. 2014.

Lecon, C., \& Herkersdorf, M. (2014). Virtual blended learning - Virtual 3D worlds and their integration in teaching scenarios. $9^{\text {th }}$ International Conference on Computer Science and Education. Aug. 2014, Vancouver (Canada).

Lueckemeyer, G. (2015). Virtual blended learning enriched by gamification and social aspects in programming education. $10^{\text {th }}$ International Conference on Computer Science and Education. Cambridge (UK), July 2015.

Lombard, M., \& Ditton. Th. (1997). At the heart it all: The concept of presence. Journal of Computer-Mediated Communication, 3(2).

\footnotetext{
${ }^{3}$ http://www.lehrforum.de/GHD/Lehrprojekt/Details/700 (in German).
} 
Mantovani, F., \& Castelnuovo, G (2003). Sense of presence in virtual training: Enhancing skills acquisition and transfer of knowledge through learning experience in virtual environments. In G. Riva, F. Davide, \& W.A. Ijsselsteijn (Eds.), Being there: concepts, effects and measurement of user presence in synthetic environments. Amsterdam: IOS Press.

Macy, M.W. (1990). Learning theory and the logic of critical mass. American Sociological Review, 55(6), 809-826.

PEW Research (2014). Social media usage by age group over time. Retrieved August 21, 2015 from http://pewrsr.ch/Vhqb6S.

Moskaliuk, J., Bertram, J., \& Cress, U. (2013). Training in virtual environments: putting theory into practice. Ergonomics, 56(2), 195-204. doi:10.1080/00140139.2012.745623.

Softic, S. Tarahi, B., Ebner, M., De Vocht, L. Mannes, E., \& Van De Valle, R. (2013). Monitoring learning activities in PLE using semantic modelling of learner behavior. In A. Holzinger, M. Zielfle, M. Hitz, \& M. Debevc (Eds.), Human Factors in Computing and Informatics: First International Conference SouthCHI 2013, 74-90. Springer Berlin Heidelberg.

Teyseyre, A., \& Campo, M. (2008). An overview of 3D software visualization. IEEE Transaction on Visualization and Computer Graphics [not published].

Trindade, J., Fiolhais, C., \& Almeida, L. (2002). Science learning in virtual environments: a descriptive study. British Journal of Educational Technology, 33(4), 471-488.

VLE (2012). Virtual Learning Environments: Concepts, Methodologies, Tools and Applications, vol. 1, 885ff. USA: Information Resource Management Association.

\section{Appendix}

Questionnaire (in German)

Abschluss-Fragebogen TriCAT Spaces - HTW Aalen

Sehr geehrte Studierende,

wir von TriCAT, das Grundlagenzentrum und der Studiengang Informatik der Hochschule Aalen möchten uns herzlich bei Ihnen für Ihr Feedback zu den virtuellen Sessions bedanken. Wir hoffen, die ein- oder andere Session hat Ihnen auch Spaß gemacht!

Ihre abschließende Meinung ist uns wichtig. Es würde uns sehr freuen, wenn Sie sich noch einmal kurz die Zeit nehmen und die Abschlussfragen beantworten.

Geben Sie bitte zu nachfolgenden Kategorien Ihr freies Feedback - gerne auch ausführlich.

Vielen Dank und viele Grüße

Ihr TriCAT Team, das Grundlagenzentrum ${ }^{4}$ und der Studiengang Informatik ${ }^{5}$ der Hochschule Aalen

\footnotetext{
4 Repräsentiert durch Bernd Oder

5 Repräsentiert durch Christian Heinlein und Carsten Lecon
} 


\section{IHRE DATEN:}

Semester:

\section{Datum:}

Speichern Sie den ausgefüllten Fragebogen bitte ab und senden Sie ihn bitte zurück an: christian.heinlein@htw-aalen.de. Herzlichen Dank für Ihre Mitarbeit!

\section{PROGRAMIMSTART und AKTUALISIERUNG}

Ihre Kommentare:

\section{EINTRETEN IN SESSION}

Ihre Kommentare:

VERBINDUNGSQUALITÄT während der Veranstaltung

Ihre Kommentare:

\section{SPRACHQUALITÄT VoIP}

Ihre Kommentare:

\section{MEDIA-WALL und 3D-VIEWER}

Ihre Kommentare:

\section{TUTORIUM ANALYSIS}

Was halten Sie generell von dieser Möglichkeit?

Ihre Kommentare:

Waren die Tutorien hilfreich für die Vorbereitung auf die (Zwischen-) Klausur?

Ihre Kommentare:

Für welche Fächer könnten Sie sich virtuelle Tutorien vorstellen?

Ihre Kommentare:

Ist die Dauer (zwei Stunden) ok?

Ihre Kommentare: 
Fühlten Sie sich durch die „geschützte“ Darstellung als (abstrakter) Avatar eher zur Aktivität (Fragen, Antworten, ...) bereit?

Ihre Kommentare:

Was würden Sie sich bei einer Weiterentwicklung wünschen?

Ihre Kommentare:

Könnten Sie sich vorstellen, einen virtuellen 3D-Raum allgemein für Gruppenarbeiten zu nutzen?

Ihre Kommentare:

Ist Ihnen im virtuellen Raum unwohl gewesen (Übelkeit, Schwindel, ..)?

Ihre Kommentare:

\section{MAC VERSION}

Ihre Kommentare: 